\title{
Synthesis and Photochromism Studies of 1-[2-methyl-5-(2-pyridyl)-3-thienyl]-2-[2- methyl-5-(4-bromomethylphenyl)-3-thienyl] Perfluorocyclopentene
}

\author{
Xugang Tang, Hongliang Liu*, Shouzhi Pu \\ Jiangxi Key Laboratory of Organic Chemistry \\ Jiangxi Science and Technology Normal University \\ Nanchang 330013, P.R.China \\ e-mail: liuhongliang03@163.com
}

\begin{abstract}
A new photochchromic diarylethene was synthesized and explored, which is named 1-[2-methyl-5-(2pyridyl)-3thienyl]-2-[2-methyl-5- (4-bromomethylphenyl) -3thienyl]perfluorocyclopentene. The results showed that it have excellent photochromism, accompanied with the color change from colorless to blue, by photoirradiation in acetonitrile. When irradiated with UV light, the absorbance at $298 \mathrm{~nm}$ decreased, while the absorption at $598 \mathrm{~nm}$ increased significantly in acetonitrile. In acetonirile, the kinetic experiments showed that the cyclization/cycloreversion process of 10 was determined to be the zeroth/first reaction.
\end{abstract}

Keywords-diarylethene; photochromism; zeroth/first
reaction; concentration

\section{INTRODUCTION}

Upon irradiation with UV light, photochromic molecules have proven extremely the fascinating ability to change their structural and electronic properties [1], which can reversibly transform from the colorless ring-open form to the colored ring-closed form. Among all types of photochromic molecules, diarylethenes are one of the most successful superior thermal stability and excellent fatigue resistance, which is crucial for their applications [2, 3]. Besides, the photochemical properties of the diarylethenes can be modified through structural variations influencing the absorption spectra, fluorescence, quantum yields, and fatigue resistance. Diarylethenes have two aryl moieties, which strongly influence the photochromic properties of diarylethene[3, 4]. For example, diarylethenes bearing thiophene moiety and six-membered pyridine unit exhibited good photochromism both in solution and in the crystalline phase by permitting the pyridine unit to participate in the photoinduced cyclization reaction [5-7]. What's more, the bearing of heteroatom of diarylethenes can dramatically change photochromism properties and expand multiple responsive switching systems $[8,9]$. Herein, we have designed and synthesized a new diarylethene bearing thiophene moiety and pyridine unit, namely 1-[2-methyl-5(2-pyridyl-3thienyl]-2-[2-methyl-5-(4-bromomethylphenyl)3- thienyl]perfluorocyclopentene. Its photochromic and the kinetic experiments were investigated in detail. The photochromic reacion of diarylethene 10 is shown in scheme 1.

\section{EXPERIMENTS}

The synthetic route for 10 is shown in Scheme 2. The intermediate products 2, 3 were synthesized according to the procedures of similar reported methods $[10,11]$. Then, compound 2 was reduced and to give the unsymmetrical diarylethene derivative 3. Finally, a stirred anhydrous $\mathrm{CH}_{2} \mathrm{Cl}_{2}$ of compound 3 was added methanesulfonyl chloride $(\mathrm{MsCl})$, triethylamine (TEA) with vigorous stirring in the ice-water bath. Stirring was continued for $5 \mathrm{~min}$. at $273 \mathrm{~K}$, $10 \mathrm{~mL}$ anhydrous THF containing $\mathrm{LiBr}$ was added and the reaction mixture was stirred for $30 \mathrm{~min}$ at this temperature. After, the mixture has been stirred for $12 \mathrm{~h}$ at room temperature. The crude product was purified by column chromatography on $\mathrm{SiO}_{2}$ using ethyl acetate as an eluent to give $1 \mathrm{O}$ as faint blue solid. $1 \mathrm{O}$ was confirmed by $1 \mathrm{H} \mathrm{NMR}$ (400 MHz, $\left.\mathrm{CDCl}_{3}, \mathrm{TMS}\right): \delta 1.98\left(\mathrm{~d}, 3 \mathrm{H},-\mathrm{CH}_{3}\right), 2.02(\mathrm{~s}, 3 \mathrm{H}$, $\left.-\mathrm{CH}_{3}\right), 4.50$ (s, 1H, -CH-), 4.64 (s, H, -CH-), 7.10 (s, 1H, thiophene-H), $7.31(\mathrm{~d}, 2 \mathrm{H}$, phenyl-H), 7.46(d, $2 \mathrm{H}$, phenylH), 7.60 (s, H, thiophene-H), 7.81 (d, H, pyridyl-H), 8.19 (s, $1 \mathrm{H}$, pyridyl-H), 8.34 (s, H, pyridyl-H), 8.81(s, H, pyridyl$\mathrm{H})$,

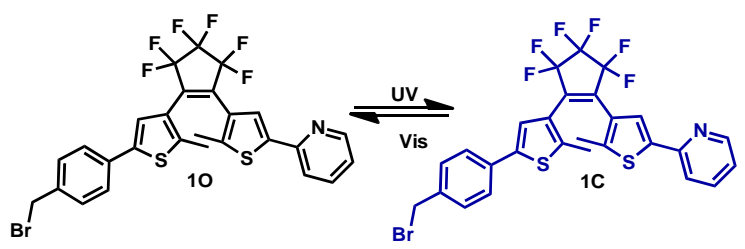

Scheme 1. Photochromism of diarylthene $\mathbf{1 0}$.

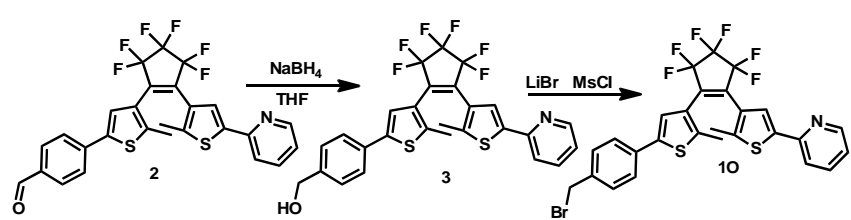

Scheme 2. Synthetic route of the compound 10 . 


\section{RESUlts AND DiscuSSION}

\section{A. Photochromism of Diarylethene in acetonitrile solution.}

The photochromic properties of diarylethenes $\mathbf{1 0}$ were measured at room temperature in acetonitrile $\left(2.0 \times 10^{-5} \mathrm{~mol}\right.$ $\left.\mathrm{L}^{-1}\right)$. Figure 1 shows the changes of absorption spectral and color of 10 in acetonitrile $\left(2.0 \times 10^{-5} \mathrm{~mol} \mathrm{~L}^{-1}\right)$ under irradiation with $297 \mathrm{~nm}$ UV light. The absorption maximum of colorless open-ring isomer was observed at $298 \mathrm{~nm}(\varepsilon=$ $2.59 \times 10^{4} \mathrm{~mol}^{-1} \mathrm{~L} \mathrm{~cm}^{-1}$ ) in acetonitrile, as a result of a $\pi \rightarrow$ $\pi^{*}$ transition [12]. Upon irradiation with $297 \mathrm{~nm}$ UV light, the colorless solution of 10 was converted into a blue solution of the closed-ring isomer $1 \mathrm{C}$ with a new visible absorption band centered at $598 \mathrm{~nm}\left(\varepsilon=1.27 \times 10^{4} \mathrm{~mol}^{-1} \mathrm{~L}\right.$ $\left.\mathrm{cm}^{-1}\right)$. Alternatively, the blue color of $1 \mathrm{C}$ could be completely bleached upon irradiation with visible light $(\lambda>$ $500 \mathrm{~nm}$ ), indicating $1 \mathrm{C}$ was returning to the initial state 10 .

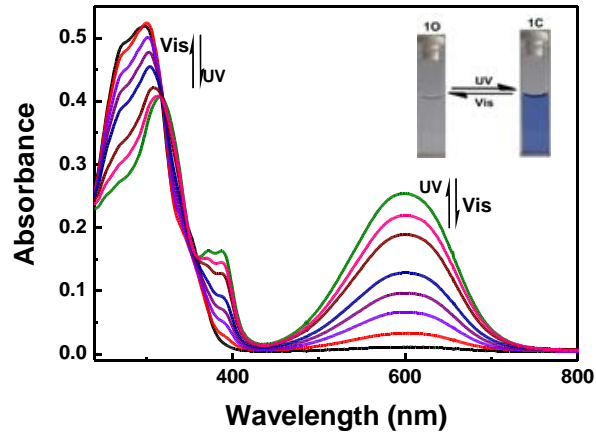

Figure 1. Absorption spectra and color change of diarylethene 10 with stimulation of $297 \mathrm{~nm}$ light in acetonitrile $\left(2.0 \times 10^{-5} \mathrm{~mol} \mathrm{~L}^{-1}\right)$ at room temperature.

\section{B. Photochromic reaction kinetics in acetonitrile solution.}

The photochromic cyclization/cycloreversion kinetics of 10 was studied by UV-Vis spectra upon irradiation at 297 $\mathrm{nm}$ (open-closed) or visible light ( $>500 \mathrm{~nm}$ ) (closedopen). As shown in Figure 2 and Figure 3, it can be seen clearly that the relationships between absorbance and exposal time have good linearity (linear correction factors $>$ 0.99) upon irradiation with $297 \mathrm{~nm}$ UV light, indicating that the cyclization process of the photochromic diarylethene 10 should belong to zeroth order reaction. The slope of line in Figure 2 represents the reaction rate constant $k$ in acetonitrile, and $k\left(1.93 \times 10^{-3} \mathrm{~S}^{-1}\right)$ of cyclization process $\left(\mathrm{k}_{\mathrm{o}-\mathrm{c}}, 10^{-3}\right)$ can be easily obtained in figure. At the same time, during the cycloreversion process of $1 \mathrm{C}$ in acetonitrile, the relationships between $-\log \mathrm{A}$ and exposal time also show perfect linearity (Figure 3$)$. The values of $k\left(\mathrm{k}_{\mathrm{c}-\mathrm{o}}, 10^{-1}\right)$ are $0.72 \times 10^{-3} \mathrm{~S}^{-1}$.

\section{Fluorescence intensity of different concentration diarylethene 10.}

The concentration depending on the fluorescence spectrum of diarylethene 10 was measured in acetonitrile at room temperature, as shown in Figure 4 . With the concentration increasing of 10 from $1.0 \times 10^{-6}$ to $5.0 \times 10^{-5}$ mol L ${ }^{-1}$, the emission remains at $475 \mathrm{~nm}$ when excited at $339 \mathrm{~nm}$ and the fluorescence relative intensity increased, but when the concentration increased to $2.010^{-4} \mathrm{~mol} \mathrm{~L}^{-1}$, the fluorescence intensity decreased rapidly. The results show that the fluorescence of 10 is remarkably concentration dependent, and shows a remarkable initial increase with subsequent dramatic decrease with increasing concentration.

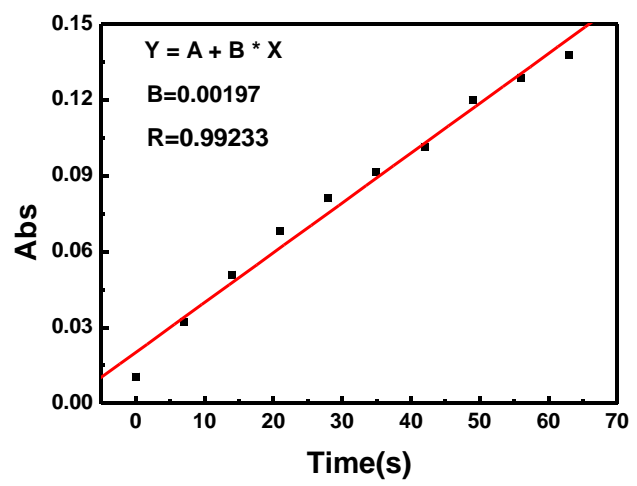

Figure 2. The kinetics of compound $\mathbf{1 0}$ in acetonitrile: cyclization.

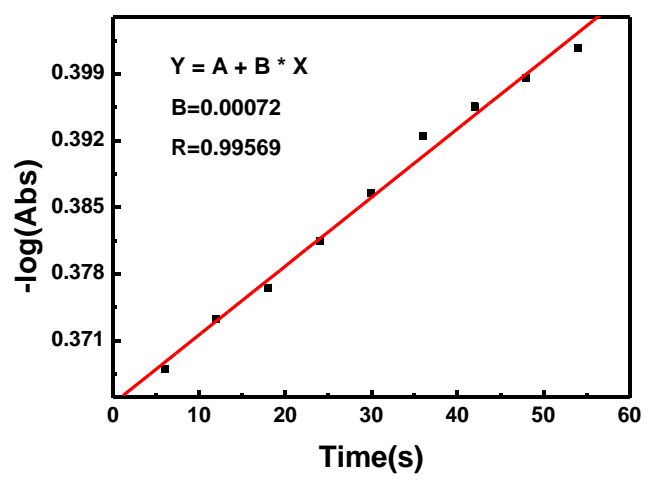

Figure 3. The kinetics of compound $\mathbf{1 0}$ in acetonitrile: cycloreversion.

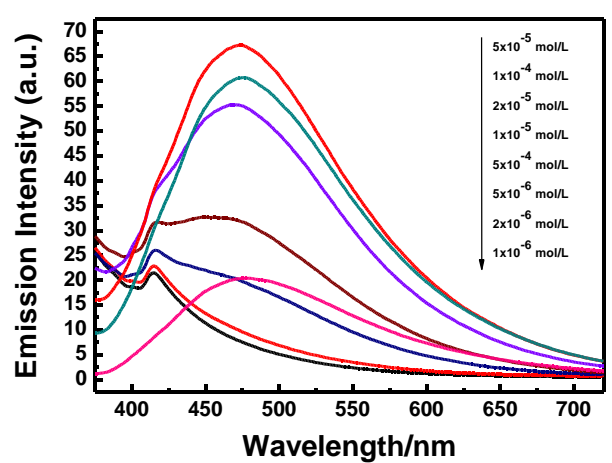

Figure 4. Fluorescence spectra of diarylethene $\mathbf{1 0}$ in various concentrations in acetonitrile excited at $339 \mathrm{~nm}$ at room temperature. 


\section{SUMmary}

An unsymmetrical diarylethene was synthesized to investigate its photochromic and fluorescent properties. The cyclization/cycloreversion process of the photochromic diarylethene 10 should belong to zeroth/first order reaction. Diarylethene 10 showed the fluorescence of 10 is remarkably concentration dependent, and shows a remarkable initial increase with subsequent dramatic decrease with increasing concentration.

\section{ACKNOWLEDGMENT}

The authors are grateful for the financial support from the National Natural Science Foundation of China (21362013, 51373072), and the Masters' Innovative Foundation of Jiangxi Science \& Technology Normal University (YC2014-X05).

\section{REFERENCES}

[1] F. M. Raymo and M. Tomasulo, "Electron and energy transfer modulation with photochromic switches," Chem. Soc. Rev. vol. 34, 2005, pp. 327-336, doi: 10.1039/B400387J.

[2] M. Irie, "Diarylethenes for memories and switches," Chem. Rev. vol. 100, 2000, pp. 1685-1716, doi:10.1021/cr980069d.

[3] S. Pu, G. Liu, L. Shen and J. Xu, "Efficient synthesis and properties of isomeric photochromic diarylethenes having a pyrrole unit,". Org. Lett. vol. 9, 2007, pp. 2139-42. doi:10.1021/o1070622q.

[4] H. Tian and S. Yang, "Recent progresses on diarylethene based photochromic switches," Chem. Soc. Rev. vol. 33, 2004, pp. 85-97, doi:10.1039/B302356G.
[5] G. Liu, S. Pu, X. Wang, W. Liu and C. Fan, "The effect of the cyano group position upon unsymmetrical isomeric diarylethenes bearing a pyrrole unit," Dyes Pigm. vol. 90, 2011, pp. 89-99. doi:10.1016/j.dyepig.2010.12.007.

[6] S. Pu, H. Li, G. Liu, W. Liu, S. Cui and C. Fan, "Synthesis and the effects of substitution upon photochromic diarylethenes bearing an isoxazole moiety," Tetrahedron. vol. 67, 2011, pp. 1438-47. doi:10.1016/j.tet.2010.12.041.

[7] S. Pu, R. Wang, Liu. G, Liu. W, S. Cui, and P, Yan, "Photochromism of new unsymmetrical diarylethene derivatives bearing both benzofuran and thiophene moieties," Dyes Pigm. vol. 94, 2012, pp. 195-206, doi:10.1016/j.dyepig.2012.01.003

[8] M. Milek, FW. Heinemann, and MM. Khusniyarov, "Spin crossover meets diarylethenes: efficient photoswitching of magnetic properties in solution at room temperature," Inorg Chem 2013; 52:11585-92. doi: $10.1021 / \mathrm{ic} 401960 \mathrm{x}$

[9] H. Wong, W. Wong, and V. Yam, "Photochromic thienylpyridineebis(alkynyl)borane complexes: toward readily tunable fluorescence dyes and photoswitchable materials," Org Lett 2012; 14:1862-5. doi: 10.1021/o13004595.

[10] F. Sun, S. Cui, G Liu, C Zheng, and S Pu, "Photochromism of isomeric diarylethenes with a methylpyridine substituent," Journal Mole Stru 2015, 1086 131-137. doi: 10.1016/j.molstruc.2015.01.015.

[11] S. Pu, L. Ma, G. Liu, H. Ding, and B. Chen, "A multiple switching diarylethene with a phenyl-linked rhodamine B unit and its application as chemosensor for $\mathrm{Cu}^{2+}$," Dyes Pigm. vol. 113, 2015, pp. 70-77, doi: 10.1016/j.dyepig.2014.07.030.

[12]Z. Li, L. Liao, W. Sun, C. Xu, C. Zhang, and C. Fang, et al "Reconfigurable cascade circuit in a photo- and chemical-switchable fluorescent diarylethene derivative," Journal of Physical Chemistry C. vol. 112, 2008, pp. 5190-6, doi:10.1021/jp711613y. 